\title{
MOLECULAR DOCKING AND PHARMACOKINETIC PREDICTION OF HERBAL DERIVATIVES AS MALTASE-GLUCOAMYLASE INHIBITOR
}

\author{
PETER JUMA OCHIENG ${ }^{1,3 *}$, TONY SUMARYADA ${ }^{1,2}$, DANIEL OKUN $^{3}$
}

${ }^{1}$ Department of Physics, Computational Biophysics and Molecular Modeling Research Group, Bogor Agricultural University, Bogor 16680, Indonesia. ${ }^{2}$ Tropical Biopharmaca Research Center, Bogor Agricultural University, (IPB), Jl. Taman Kencana No. 3, Bogor 16680, Indonesia. ${ }^{3}$ Department of Biochemistry and Biotechnology, Kenyatta University, P.O.BOX 43844-00100, Nairobi, Kenya.

Email: peter_ochieng@apps.ipb.ac.id

Received: 21 April 2016, Revised and Accepted: 02 June 2017

\section{ABSTRACT}

Objective: To perform molecular docking and pharmacokinetic prediction of momordicoside F2, beta-sitosterol, and cis-N-feruloyltyramine herbal derivatives as maltase-glucoamylase (MGAM) inhibitors for the treatment of diabetes.

Methods: The herbal derivatives and standard drug miglitol were docked differently onto MGAM receptor using AutoDock Vina software. In addition, Lipinski's rule, drug-likeness, and absorption, distribution, metabolism, excretion, and toxicity (ADMET) properties were analyzed using Molinspiration, ADMET structure-activity relationship, and prediction of activity spectra for substances online tools.

Results: Docking studies reveal that momordicoside F2, beta-sitosterol, and cis-N-feruloyltyramine derivatives have high binding affinity to the MGAM receptor $(-7.8,-6.8$, and $-6.5 \mathrm{Kcal} / \mathrm{Mol}$, respectively) as compared to standard drug miglitol ( $-5.3 \mathrm{Kcal} / \mathrm{Mol})$. In addition, all the herbal derivatives indicate good bioavailability (topological polar surface area $<140 \dot{\mathrm{A}}$ and $N_{\text {rot }}<10$ ) without toxicity or mutagenic effects.

Conclusion: The molecular docking and pharmacokinetic information of herbal derivatives obtained in this study can be utilized to develop novel MGAM inhibitors having antidiabetic potential with better pharmacokinetic and pharmacodynamics profile.

Keywords: Absorption; distribution; metabolism; excretion; and toxicity, Herbal derivatives, Maltase-glucoamylase, Molecular docking, Pharmacokinetics.

(C) 2017 The Authors. Published by Innovare Academic Sciences Pvt Ltd. This is an open access article under the CC BY license (http://creativecommons. org/licenses/by/4. 0/) DOI: http://dx.doi.org/10.22159/ajpcr.2017.v10i9.19337

\section{INTRODUCTION}

Diabetes syndrome is a metabolic disorder, which causes congenital (type I insulin-dependent) or acquired (type II noninsulin-dependent) diabetes mellitus, and approximately $7 \%$ of the world population is suffering from this chronic disorder [1-4]. This chronic disease not only affects the carbohydrate metabolism but also alters lipid and protein metabolism in advanced stages, leading to complications such as microvascular or macrovascular which are more fatal than the primary diabetic state; thus, all credit goes to regulating postprandial glucose levels [5-7]. One of the therapeutic approaches to regulate blood glucose level in an individual with type 2 diabetes is to inhibit R-amylases and intestinal glucosidases activity using R-glucosidase inhibitors such as acarbose and miglitol [8-10]

Currently, acarbose and miglitol are the only $\alpha$-glucosidase inhibitors which make up a class of antihyperglycemic drugs for regulating postprandial glucose levels by reversibly inhibiting digestive $\alpha$-amylases and $\alpha$-glucosidases [11-14]. Generally, it was believed that carbohydrate mimics contain nitrogen; for instance, acarbose and miglitol are protonated in the active site and act as glycosidase inhibitors due to their ability to mimic the shape or charge of the presumed transition state for enzymatic glycoside hydrolysis [15].

$\mathrm{N}$-terminal catalytic domain of maltase-glucoamylase (ntMGAM) is one of the intestinal glucosidase targets. In human's family, GH311 glycoside hydrolases MGAM is responsible for the digestion of terminal starch products left after R-amylase action into glucose. This membrane-bound enzyme contains two catalytic subunits: N-terminal subunit (ntMGAM) proximal to the membrane-bound end and C-terminal luminal subunit (ctMGAM) $[16,17]$. Therefore, to inhibit the enzyme's function, herbal drugs have been used to replace the synthetic drugs such as acarbose and miglitol which often present adverse effects to some diabetic individuals. Studies showed extracts from Momordica charantia, Tinospora cordifolia, and Zingiber officinale herbal plants to contain alkaloid compounds with $\alpha$-glucosidase inhibitory properties with hypoglycemic effect on several animal studies and small-scale human studies [18-21]. Moreover, it has been reported that consumption of $M$. charantia in raw or juice form can be efficacious in lowering blood glucose levels [22,23].

The previous study on molecular docking revealed that momordicoside $\mathrm{F} 2$, beta-sitosterol, and cis- $\mathrm{N}$-feruloyltyramine compounds have higher binding affinity to MGAM receptor with the potential to cure type 2 diabetes. However, the structural function and molecular properties for their drug-likeness remain unknown. Related on in silico studies have indicated molecular docking to be a robust and reliable approach to screen for drug-likeness of molecules [24-26]. In drug discovery, structure-based drug design is a vital tool for the discovery and development of new molecules using X-ray crystal structure of a protein from protein data bank (PDB) [27-30]. In molecular modeling, drugreceptor complex stability, exact binding mode, and ligand interaction with amino acids of the protein molecule can be visualized using various docking approaches to discover the pharmacological properties of drug molecules [31]

The current study utilizes in silico molecular docking and pharmacodynamics prediction to elucidate the drug-likeness, Lipinski's rule, and absorption, distribution, metabolism, excretion, and toxicity (ADMET) properties of momordicoside F2, beta-sitosterol, and cis-Nferuloyltyramine herbal derivatives as MGAM inhibitor. 


\section{MATERIALS AND METHODS}

\section{Ligands and protein preparation}

The three herbal derivatives were selected based on previous network pharmacology study [32]. The 3D ligands structure of beta-sitosterol (CID: 222284) from the Z. officinale herb, cis-N-feruloyltyramine (CID: 5280537, also known as Moupinamide) from Tinospora crispa herb, and momordicoside F2 (CID: 44445567) from M. charantia as well as the standard drug miglitol (CID: 441314) were all downloaded from PubChem online database [33].

The crystal structure of receptor MGAM (PDB code 2QMJ) protein was downloaded from RCSB PDB [34] at a resolution of $1.9 \AA$ and refined by subtracting water molecules as well as the addition of hydrogen bond and Gasteiger-Huckel charges. All the data files for ligands and receptor were then saved in PDBQT format.

\section{Docking protocol}

The AutoDock Vina [35] program installed in $4 \mathrm{GHz}$ Intel Core i3 processor and 4GB RAM, having Windows 8 Professional as an operating system, was utilized to perform automated docking studies to predict the protein-ligand interaction. The active site for MGAM $(2 \mathrm{QMJ})$ was selected and the grid size was set as $\mathrm{x}=-27.643, \mathrm{y}=$ -12.49 , and $\mathrm{z}=-0.559$ with the box size set to $\mathrm{z}=30, \mathrm{y}=30$, and $\mathrm{x}=36$. In addition, the number of exhaustiveness was set at 20 to compromise the global search and local minimum for optimal docking results. To validate the docking protocol for the three herbal derivatives, miglitol was used as the standard ligand. In the proposed docking protocol, ligands were kept flexible while amino acid in protein was held rigid after which each ligand was docked onto the active site of the MGAM receptor [36-38]. The scoring function (Gibbs-free energy/binding affinity) for the ligand-MGAM complex was computed using AutoDock Vina program, while interaction between MGAM amino acids residues and herbal derivatives with respect to H-bond and hydrophobic bonds on the binding sites was analyzed using LigPlot+ v.1.4 program [39].

The AutoDock Vina program uses free energy empirical scoring functions where binding energy decomposes into several energy components including hydrogen bond, ionic interaction, hydrophobic effect, and binding entropy. AutoDock scoring function is calculated by the equation below.

$$
\sum_{\text {neutralH-bond }}^{\Delta G=\Delta G_{0}+\Delta G_{\text {rot }} \times N_{\text {rot }}+\Delta G_{\mathrm{hb}}} f(\Delta R, \Delta \pm)+\Delta G_{\text {aro }} \sum_{\text {aroint }} \mathrm{f}(\Delta R, \Delta \alpha)+\Delta G_{\text {lipo }} \text { lipocontf }_{\text {in }} *(\Delta R
$$

Where $\Delta G$ is the estimated free binding energy; $\Delta G_{0}$ is the regression constant; $\Delta G_{\mathrm{rot}^{\prime}} \Delta G_{\mathrm{hb}^{\prime}} \Delta G_{\mathrm{io}^{\prime}} \Delta G_{\mathrm{aro}}$, and $\Delta G_{\text {lipo }}$ are regression coefficients for each corresponding free energy term; $f(\Delta R, \Delta \alpha)$ is scaling function for penalizing ideal geometry deviations; $\mathrm{N}_{\text {rot }}$ is the number of free rotatable bonds that are immobilized in the complex [40].

\section{Prediction of molecular properties}

Lipinski's rule of five (RO5) was used to evaluate drug-likeness to determine if the herbal derivatives have certain pharmacological or biological activity that would make them an orally active drug-like moiety for humans $[41,42]$.

Thus, essential molecular properties such as molecular weight, hydrogen bond donor, hydrogen bond acceptor, number of the rotatable bonds, and $\log \mathrm{P}$ for each herbal derivatives (momordicoside F2, cis- $\mathrm{N}-$ feruloyltyramine, and beta-sitosterol) were calculated using MedChem Designer (www.simulations-plus.com).

\section{Prediction of bioactivity score}

Bioactivity of momordicoside $\mathrm{F} 2$, cis-N-feruloyltyramine, and betasitosterol herbal derivatives can be checked by calculating the activity score of G-protein-coupled receptor (GPCR) ligand, ion channel modulator, nuclear receptor ligand, kinase inhibitor, protease inhibitor, and enzyme inhibitor [43]. All these parameters were calculated using Molinspiration drug-likeness (www.molinspiration.com), an online server database. Here, calculated drug-likeness scores for each herbal derivative were then compared with that of standard drug miglitol.

\section{Prediction of ADMET properties for the herbal derivatives}

Drugs are often withdrawn at the different phases of the clinical trials due to poor ADMET properties and adverse effects probably associated with their molecular structures. Therefore, it is important to predict ADMET properties during the lead identification and optimizations. Here, we used ADMET SAR a free online server to predict ADMET properties such as blood-brain barrier (BBB)+ penetration, human intestinal absorption (HIA), biodegradability, $\mathrm{CaCO}_{2}$ permeability, AMES toxicity, carcinogenicity, rat acute toxicity. Thus, we estimated the ADMET properties of the compounds using admetSAR online database (www.lmmd.ecust.edu.cn) which comprises data for different entities linked with known ADMET profiles [44].

\section{Therapeutic target validation}

Structural feature of a molecule in drug design plays an essential role in correcting therapeutic targets or therapeutic disease. Here, prediction of activity spectra for substances (PASS), an online software tool that predicts more than 300 pharmacological effects and biochemical mechanisms of compounds based on their structural information [45], was used to screen the possible therapeutic targets for the herbal derivatives. PASS (Prediction of activity spectra for substances) software, predicted the probability of activity $(\mathrm{Pa})$ and inactivity $(\mathrm{Pi})$ values for each herbal derivatives to identify the possible inhibitory targets.

\section{RESULTS AND DISCUSSION}

In the current study, the binding affinity and binding site similarity (BSS) score for herbal derivatives and standard drug miglitol onto MGAM receptor were evaluated by molecular docking approach using AutoDock Vina software. The molecular properties and biological activity of the herbal derivatives were further analyzed by online tools to predict their pharmacokinetics and pharmacodynamics profiles as future candidate compounds to develop the antidiabetic drug.

The chemical structure and function of momordicoside F2, cis-N-Feruloyltyramine and beta-sitosterol herbal derivatives (Fig. 1) were utilized to predict scoring functions and their biological interaction with amino acid residues of MGAM receptor previously obtained from Protein Data Bank. From the docking analysis binding pattern of herbal derivatives were found to vary with the molecular conformation of the ligand [46-48].

The previous pharmacophore study showed momordicoside F1 and miglitol to have similar BSS score (100\%) to MGAM receptor. However, H-bond interactions for both compounds with MGAM were different. Miglitol compound was involved in H-bond interaction with four amino acid residues (Asp702, Leu727, Ile 725 and Glu719) of MGAM with binding affinity of $-5.3 \mathrm{Kcal} / \mathrm{Mol}$ whereas, momordicoside F1 interacted with Gln 708, Glu704, Try 626 and Ile725 amino acid residue with -7.8 Kcal/Mol binding affinity. In addition, the momordicoside $\mathrm{F} 2$ compound was also involved in H-bond interaction with seven amino acids of MGAM protein (Lys724, Asp702, leu720, Glu719, leu727, Glu704, and Ile725). On the other hand, cis-N-feruloyltyramine compounds showed a binding pattern with 12 different amino acids residues with six amino acid residues involved in $\mathrm{H}$-bond and hydrophobic interaction at target binding site where four amino acid residues (Glu719, Leu720, Asp702, and Lys 724) were involved in the H-bond interaction while two amino acid residues (Ile 725 and Glu704) involved in hydrophobic interaction with BSS score $(85.71 \%)$ and binding affinity $(-6.50 \mathrm{Kcal} / \mathrm{Mol})$.

Beta-sitosterol demonstrated high BSS score $(85.71 \%)$ and binding affinity $(-6.8 \mathrm{Kcal} / \mathrm{Mol})$ with MGAM receptor. This explains that its antidiabetic potential is due to hydrophobic interactions with MGAM amino acids residues (Ile725, Glu704, Lys724, Glu719, Asp702, and Leu720) with the absence of $\mathrm{H}$-bond interaction. The molecular 


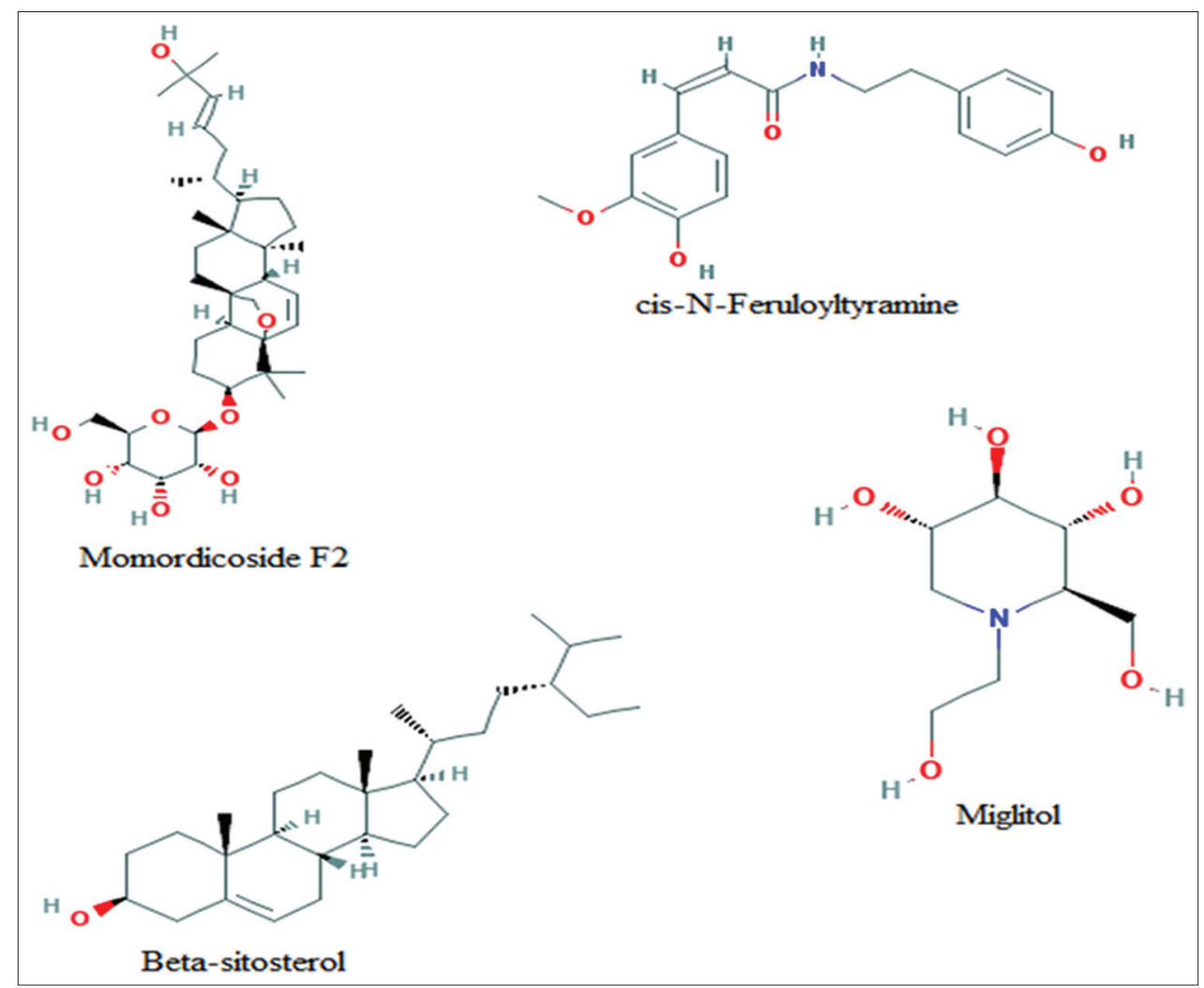

Fig. 1: Chemical structures of momordicoside F2, cis-N-feruloyltyramine, beta-sitosterol, and standard drug miglitol

docking revealed that the hydrophobic pocket of MGAM comprises nine interaction amino acid residues where four residues (Asp702, Leu727, Ile 725, and Glu719) are responsible for hydrogen bond formation during the interaction while five residues (Hsd728, Gly726, Leu720, Glu704, and Lys 724) form a hydrophobic pocket responsible for direct or indirect hydrophobic interaction. Previous studies have reported that the linker between the polar head and hydrophobic tail plays an important role in binding the ligand with MGAM [49-51]. The previous pharmacophore study revealed three herbal derivatives and standard drug miglitol to have common binding sites (Ile725, Glu704, Lys724, Leu720, Asp702, and Glu719) at MGAM binding pockets. Thus, the binding property of the herbal derivatives onto MGAM indicates their potential to inhibit MGAM activity.

To further understand the molecular properties of the herbal derivatives, we utilize Molinspiration an online tool to analyze the molecular lipophilicity potential (MLP). MLP is a useful property to rationalize various molecular ADME properties such as membrane penetration or plasma protein binding. Thus, it is important to identify which parts of their molecular surface of a compound are hydrophobic (encoded by violet and blue colors) and/or hydrophilic (encoded by orange and red). MLP analysis (Fig. 2) reveals momordicoside $\mathrm{F} 2$, beta-sitosterol, and cis- $\mathrm{N}$-feruloyltyramine to have significant hydrophobicity distribution $(83.33 \%, 100 \%$, and $66.57 \%$, respectively) whereas miglitol showed hydrophilic distribution (57.14\%). Hydrophobicity distribution on the molecular surface of the drug molecules plays an important role when distinguishing the observed ADME properties of drug molecules with respect to their lipophilicity $(\log P)$ values [52-54]. The three investigated herbal derivatives show better MLP hydrophobicity distribution as compared to miglitol drug. Therefore, we utilized the calculated MLP from atomic hydrophobicity to compute the $\log \mathrm{P}$ (Table 1).

The molecular descriptors of herbal derivatives and standard drug miglitol were evaluated for Lipinski's R05. From the analysis, cis-Nferuloyltyramine, beta-sitosterol, and miglitol compounds have molecular

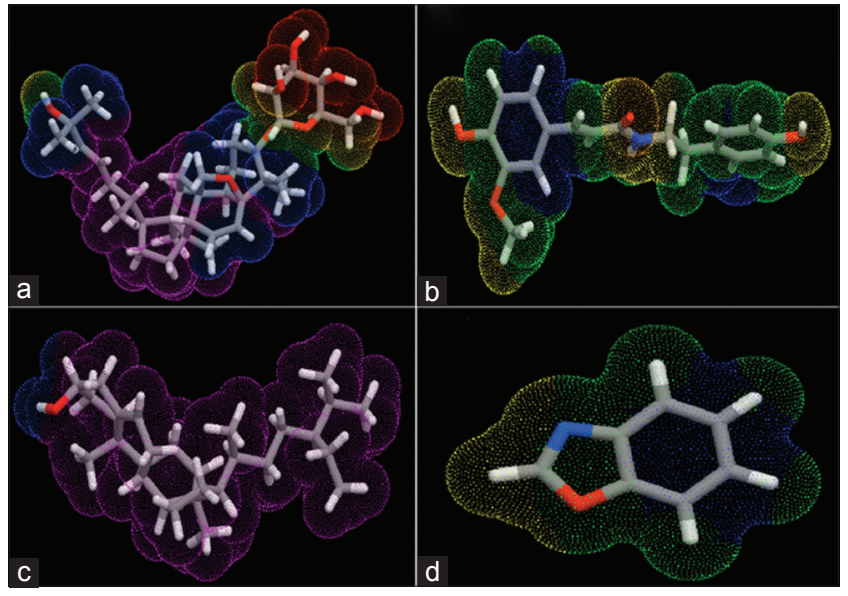

Fig. 2: Surface representation of molecular lipophilicity potential for (a) momordicoside $\mathrm{F} 2$, (b): Cis- $\mathrm{N}$-feruloyltyramine, (c) betasitosterol, and (d) standard drug miglitol. The hydrophobic surface are encoded by violet and blue colors and hydrophilic surface with orange and red colors

weight within the range of 200-500 g/Mol, except for momordicoside F2 (618.852 g/Mol) which exceeds the Lipinski's limit. Molecular weight plays an important role with respect to drug action because as the molecular weight increases beyond the certain limit, the surface area of the compound also increases correspondingly; consequently, this affects the penetrability of the drug compound [55,56]. Likewise, cis$\mathrm{N}$-feruloyltyramine, beta-sitosterol, and miglitol had similar range for molecular volume, except momordicoside F2 which exceeded the range (603.90). Molecular volume of drug molecule determines its transport characteristics such as intestinal absorption or BBB penetration; hence, it is an important parameter when evaluating molecular properties and biological activity of the investigated herbal derivatives. 


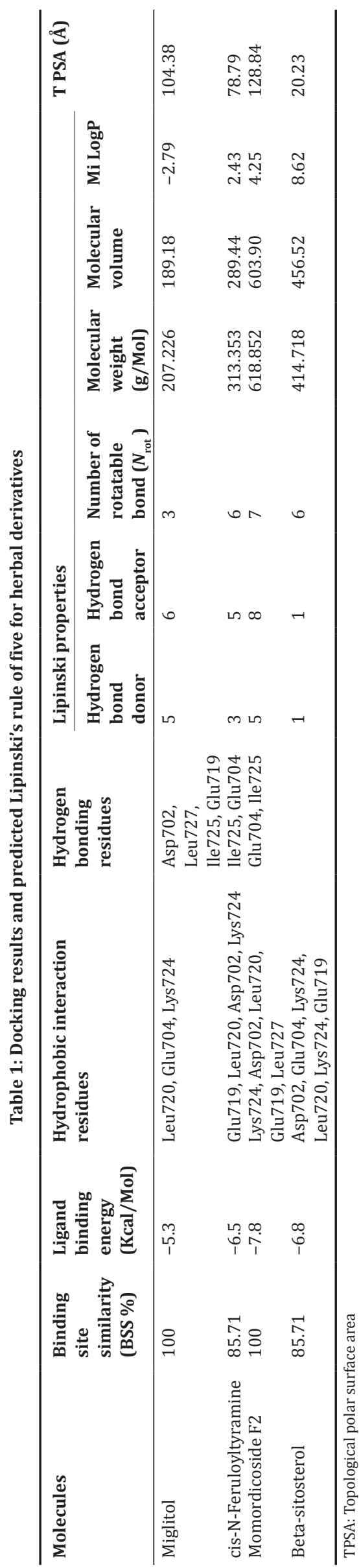

Prediction of transport properties for herbal derivatives was critical to determine their correlation with the $\mathrm{HIA}, \mathrm{CaCO}_{2}$ monolayers permeability, and $\mathrm{BBB}$ penetration. As mentioned previously in the analysis of MLP, lipophilicity ( $\log$ ) and topological polar surface area (TPSA) play two major factors which influence the permeability of the compounds as well as determine oral bioavailability [57]. The TPSA was obtained by calculating the total surface areas occupied by oxygen and nitrogen atoms as well as hydrogen attached to these molecules. This revealed the relationship of the potential of hydrogen bonding with the TPSA value of those compounds. The lipophilicity for the herbal compound and standard drug miglitol was analyzed by Molinspiration online tool and was found to be $\log \mathrm{P}<10$. In addition, it has been reported that compounds having TPSA $\leq 140 \dot{A}$ and rotational bonds $N_{\text {rot }} \leq 10$ are more likely to have good bioavailability due to rotational bonds that make the compounds flexible, hence easily interact with specific rigid binding area [58]. The results indicated that all herbal derivatives and standard drug miglitol demonstrated good numbers of rotational bonds and TPSA value within limits (Table 1).

Drug solubility alongside permeability plays a vital role since those parameters often influence the pharmacokinetic and pharmacodynamics properties of drugs starting from the site of administration, absorption into systemic circulation, and movement in the blood and excretion. Therefore, ADMET of the compounds was calculated using online dataset admetSAR mention previously in the materials and methods section. In this analysis, different permeability such as $\mathrm{BBB}$ penetration, $\mathrm{HIA}, \mathrm{CaCO}_{2}$ cell permeability, renal organic cation transport, and AMES toxicity were tested. A study has shown that cytochrome P450 (CYP) enzymes are mainly involved in the drug metabolism for elimination and biotransformation. Furthermore, it has been reported that drug-drug interactions can activate or inhibit CYP enzymes; thus, coadministration of the drug may accumulate to toxic level due to inhibition of CYP enzymes or rapid excretion due to activation of CYP microsomal enzymes [59]. In clinical pharmacology, P-glycoproteins are the main reason for drug resistance (low cell susceptible to drugs). These proteins are often involved in the efflux and their activation would lead to increase in drug efflux, hence lowering drug concentration below the minimum required level which may result in therapeutic failure [60].

The three investigated herbal derivatives did not show interaction with P-glycoprotein (Table 2). Apart from P-glycoproteins, tumorigenic or carcinogenic may also have a direct or indirect correlation with the molecular properties of those compounds. Thus, carcinogenicity, oral toxicity, and acute dose toxicity in the rat $\left(\mathrm{LD}_{50}\right)$ of the three compounds were also tested and the results summarized in supplementary file S2. Based on the admetSAR results, all the herbal derivatives can permit through the intestine barrier and absorbed from the human intestine without any toxicity or mutagenicity.

Most drugs often act by interacting with different GPCR ligands, nuclear receptors, or different kind of enzymes, ion channels, protease, viz., kinase. Interaction of chemical compounds with these biomolecules tends to indicate their drug-likeness.

Thus, all the herbal derivatives were screened for their drug-likeness using Molinspiration online tool previously mentioned in the Materials and Methods section (comprehensive results are provided in supplementary file S1). In the analysis, it was hypothesized that molecules having a positive biological value (more than 0.00 ) are supposed to have good biological activity and those having biological score $<-0.50$ are considered to be biologically inactive while compounds with value in between -0.50 and 0.00 are recognized as a mild to moderate active [61]. All the compounds were docked different onto MGAM receptor (a brush border membrane enzyme responsible for digestion dietary starch to glucose) with assumption that the herbal derivatives possess good MGAM inhibitory activity. The predicted biological score (Table 3 ) indicate that all compounds were biologically 
active with a good biological score $<0.00$, thus capable of having pharmacological action through interaction with the enzyme receptor.

Although miglitol compound indicated the poor biological score for nuclear receptors $(-0.82)$, study has reported miglitol drug to have significant biological activity with MGAM in streptozotocin-induced diabetic rats [62]. Both momordicoside F2 and beta-sitosterol herbal derivatives showed a good biological score for kinase inhibition, which may modulate disease state by an alteration in the signal cascading pathway. Furthermore, we performed in silico validation using PASS online software to check the common therapeutic activities for the three investigated herbal derivatives and summarized results in supplementary file S3. The results revealed the herbal derivatives were mainly involved in R-glucosidase, mannosidase, and GPCR kinase 2 (GRK2) inhibitory activities (Table 4). This indicates that momordicoside $\mathrm{F} 2$, cis- $\mathrm{N}$-feruloyltyramine, and beta-sitosterol herbal derivative may act as R-glucosidase inhibitor by competitively and reversibly inhibiting alpha-glucosidase in the intestines. Thus, this inhibition lowers the rate of glucose absorption through delayed carbohydrate digestion and extended digestion time $[63,64]$. Hence, the three herbal derivatives may have the probably cure diabetic disease by inhibiting MGAM activity. In addition, momordicoside F2, cis- $\mathrm{N}$-feruloyltyramine, and beta-sitosterol herbal derivatives act as a GRK2 inhibitor. GRK2 can act as an inhibitor of insulin-mediated glucose transport stimulation in 3T3L1 adipocytes by interacting with Gaq/11 function independently of its kinase activity [65]. GRK2 also inhibits basal and insulin-stimulated glycogen synthesis in mouse liver FL83B cells [66]. In that context, PASS validation results revealed that the investigated herbal derivatives have higher probability of inhibiting GRK2 activity and this may play a relevant physiological role in the modulation of insulin responses [67,68]. Studies have shown GRK2 expression is increased in key tissues in different experimental models of insulin resistance, and a 50\% downregulation of GRK2 levels in hemizygous $\mathrm{GRK}^{+/-}$mice is sufficient to protect against TNF- $\alpha$, aging, or high-fat diet-induced alterations in glucose homeostasis and insulin signaling, strongly arguing for a key role for GRK2 in the modulation of insulin sensitivity in physiological and pathological conditions [69,70]. From this analysis, momordicoside F2, cis- $\mathrm{N}$-feruloyltyramine, and beta-sitosterol herbal derivatives show a significant therapeutic activity with glucosidases and GRK2; thus, the herbal derivatives may be promising lead compounds for the development of other MGAM inhibitors.

\section{CONCLUSION}

Discovery of new alpha-glucosidase (MGAM) inhibitors with potential biological activity and minimal or no adverse effect is an exigent need for efficient treatment of diabetes. The current study successfully utilizes molecular docking and pharmacokinetic predictions of momordicoside F2, cis-N-feruloyltyramine, and beta-sitosterol herbal derivatives as MGAM inhibitor in the treatment of diabetes disease. Docking results revealed the three investigated herbal derivatives significantly interaction with MGAM amino acid residues in respect

Table 2: Predicted ADMET properties for herbal derivatives and standard drug miglitol

\begin{tabular}{llllllcr}
\hline Molecules & $\begin{array}{l}\text { Human } \\
\text { intestinal } \\
\text { absorption }\end{array}$ & $\begin{array}{l}\text { CaCO-2 } \\
\text { permeability }\end{array}$ & $\begin{array}{l}\text { P-glycoprotein } \\
\text { substrate }\end{array}$ & $\begin{array}{l}\text { Renal } \\
\text { organic } \\
\text { cation } \\
\text { transporter }\end{array}$ & $\begin{array}{l}\text { CYP450 3A4 } \\
\text { inhibitor }\end{array}$ & $\begin{array}{l}\text { CYP450 2D6 } \\
\text { inhibitor }\end{array}$ & $\begin{array}{l}\text { CYP } \\
\text { inhibitory } \\
\text { promiscuity }\end{array}$ \\
\hline Miglitol & 0.5422 & 0.7375 & 0.6354 & 0.6749 & 0.9931 & 0.9535 \\
inhibition
\end{tabular}

ADMET: Absorption, distribution, metabolism, excretion, and toxicity, CYP: Cytochrome P450, HIA: Human intestinal absorption, ${ }^{\dagger}$ Significant value

Table 3: Predicted biological interaction for herbal derivatives and standard drug miglitol

\begin{tabular}{llllllll}
\hline Molecules & $\begin{array}{l}\text { GPCR } \\
\text { ligand }\end{array}$ & $\begin{array}{l}\text { Ion } \\
\text { channel } \\
\text { modulator }\end{array}$ & $\begin{array}{l}\text { Kinase } \\
\text { inhibitor }\end{array}$ & $\begin{array}{l}\text { Nuclear } \\
\text { receptor } \\
\text { ligand }\end{array}$ & $\begin{array}{l}\text { Protease } \\
\text { inhibitor }\end{array}$ & $\begin{array}{l}\text { Enzyme } \\
\text { inhibitor }\end{array}$ & $\begin{array}{l}\text { P-glycoprotein } \\
\text { inhibitor }\end{array}$ \\
\hline Miglitol & -0.41 & -0.10 & -0.53 & -0.82 & 0.11 & 0.36 & 0.7325 \\
inhibitor \\
cis-N-Feruloyltyramine & 0.10 & -0.06 & -0.16 & 0.05 & -0.05 & 0.02 & 0.7851 \\
Momordicoside F2 & 0.26 & -0.39 & 0.48 & 0.23 & 0.20 & 0.30 & 0.6589 \\
Beta-sitosterol & 0.14 & 0.04 & 0.51 & 0.73 & 0.07 & 0.51 & 0.681 \\
& & & & & & 0.9022 & 0.7056 \\
inhibitor & & 0.9291 \\
Non inhibitor & Non inhibitor Non inhibitor \\
\hline
\end{tabular}

GPCR: G-protein-coupled receptor, CYP: Cytochrome P450

Table 4: Common therapeutic activities for momordicoside F2, cis-N-feruloyltyramine, and beta-sitosterol herbal derivatives

\begin{tabular}{lll}
\hline Therapeutic activity & Probability of activity (Pa) & Probability of inactivity (Pi) \\
\hline Mannosidase inhibitor & 0.963 & 0.000 \\
Alpha-mannosidase inhibitor & 0.960 & 0.000 \\
Mannosyl-oligosaccharide 1,2-alpha-mannosidase inhibitor & 0.897 & 0.001 \\
Oligo-1,6-glucosidase inhibitor & 0.893 & 0.001 \\
Sucrose alpha-glucosidase inhibitor & 0.880 & 0.000 \\
Alpha-glucosidase inhibitor & $0.879^{*}$ & 0.001 \\
Glucan 1,4-beta-glucosidase inhibitor & 0.517 & 0.006 \\
G-protein-coupled receptor kinase 2 inhibitor & $0.550^{*}$ & 0.025 \\
Glucose-6-phosphate translocase inhibitor & $0.542^{*}$ & 0.006 \\
\hline
\end{tabular}

*Significant inhibitory activities 
to H-bonding and hydrophobic interaction. The similarity score and binding affinity support the hypothesis that three herbal derivatives from $Z$. officinale, T. crispa, and M. charantia medicinal plants may have substantial antidiabetic property by inhibiting MGAM activity. Moreover, pharmacodynamics prediction of a biological score and ADEMT activity indicates the three herbal derivatives could be promising lead molecules for the development of the novel antidiabetic agents, and in the future analogs, compounds hold immense potential to develop a competent therapy for diabetes. However, further in vivo and in-vitro studies will help decipher potential biological activity of the three herbal derivatives with MGAM as an alpha-glucosidase inhibitor with significant antidiabetic effects.

\section{ACKNOWLEDGMENT}

We express our gratitude to Ministry of Research and Higher Education, Republic of Indonesia, for funding part of this research project through research grant (No: 237/IT3.41.2/L2/SPK/2013 code 2013.089.521219) and also to Department of Physics, Bogor Agricultural University and Department of Biochemistry and Biotechnology, Kenyatta University for their contribution towards this project.

\section{REFERENCES}

1. Bang H, Edwards AM, Bomback AS, Ballantyne CM, Brillon D, Callahan MA, et al. Development and validation of a patient selfassessment score for diabetes risk. Ann Intern Med 2009;151(11):775-83.

2. Hamman RF. Genetic and environmental determinants of noninsulin-dependent diabetes mellitus (NIDDM). Diabetes Metab Rev 1992;8(4):287-338.

3. Shaw JE, Sicree RA, Zimmet PZ. Global estimates of the prevalence of diabetes for 2010 and 2030. Diabetes Res Clin Pract 2010;87(1):4-14.

4. Encina G, Ezquer F, Conget P, Israel Y. Insulin is secreted upon glucose stimulation by both gastrointestinal enteroendocrine K-cells and L-cells engineered with the preproinsulin gene. Biol Res 2011;44(3):301-5.

5. Cade WT. Diabetes-related microvascular and macrovascular diseases in the physical therapy setting. Phys Ther 2008;88(11):1322-35.

6. Zhang BB, Moller DE. New approaches in the treatment of type 2 diabetes. Curr Opin Chem Biol 2000;4(4):461-7.

7. Defronzo RA. Banting Lecture. From the triumvirate to the ominous octet: A new paradigm for the treatment of type 2 diabetes mellitus. Diabetes 2009;58(4):773-95.

8. Mooradian $\mathrm{AD}$, Thurman JE. Drug therapy of postprandial hyperglycaemia. Drugs 1999;57(1):19-29.

9. Krentz AJ, Bailey CJ. Oral antidiabetic agents: Current role in type 2 diabetes mellitus. Drugs 2005;65(3):385-411.

10. Holman RR, Cull CA, Turner RC. A randomized double-blind trial of acarbose in type 2 diabetes shows improved glycemic control over 3 years (U.K. Prospective Diabetes Study 44) Diabetes Care 1999;22(6):960-4.

11. Tugrul S, Kutlu T, Pekin O, Baglam E, Kiyak H, Oral O. Clinical, endocrine, and metabolic effects of acarbose, a alpha-glucosidase inhibitor, in overweight and nonoverweight patients with polycystic ovarian syndrome. Fertil Steril 2008;90(4):1144-8.

12. Asano N. Glycosidase inhibitors: Update and perspectives on practical use. Glycobiology 2003;13(10):93R-104R.

13. Bischoff H. Pharmacology of R-glucosidase inhibition. Eur J Clin Invest 1994;18(4):243-10.

14. Toeller M. Nutritional recommendations for diabetic patients and treatment with alpha-glucosidase inhibitors. Drugs 1992;44 Suppl 3:13-20.

15. Li C, Begum A, Numao S, Park KH, Withers SG, Brayer GD. Acarbose rearrangement mechanism implied by the kinetic and structural analysis of human pancreatic alpha-amylase in complex with analogues and their elongated counterparts. Biochemistry 2005;44(9):3347-57.

16. Sim L, Quezada-Calvillo R, Sterchi EE, Nichols BL, Rose DR. Human intestinal maltase-glucoamylase: Crystal structure of the N-terminal catalytic subunit and basis of inhibition and substrate specificity. J Mol Biol 2008;375(3):782-92.

17. Liu H, Nasi R, Jayakanthan K, Sim L, Heipel H, Rose DR, et al. New synthetic routes to chain-extended selenium, sulfur, and nitrogen analogues of the naturally occurring glucosidase inhibitor salacinol and their inhibitory activities against recombinant human maltase glucoamylase. J Org Chem 2007;72(17):6562-72.
18. Kaur R, Afzal M, Kazmi I, Ahamd I, Ahmed Z, Ali B, et al. Polypharmacy (herbal and synthetic drug combination): A novel approach in the treatment of type- 2 diabetes and its complications in rats. J Nat Med 2013;67(3):662-71.

19. Upadhyay AK, Kumar K, Kumar A, Mishra HS. Tinospora cordifolia (Willd.) Hook. f. and Thoms. (Guduchi) - Validation of the Ayurvedic pharmacology through experimental and clinical studies. Int J Ayurveda Res 2010;1(8):112-21.

20. Lo HY, Ho TY, Lin C, Li CC, Hsiang CY. Momordica charantia and its novel polypeptide regulate glucose homeostasis in mice via binding to insulin receptor. J Agric Food Chem 2013;61(10):2461-8.

21. Chen Q, Chan LL, Li ET. Bitter melon (Momordica charantia) reduces adiposity, lowers serum insulin and normalizes glucose tolerance in rats fed a high fat diet. J Nutr 2003;133(4):1088-93.

22. Chang CL, Lin Y, Bartolome AP, Chen YC, Chiu SC, Yang WC. Herbal therapies for type 2 diabetes mellitus: Chemistry, biology, and potential application of selected plants and compounds. Evid Based Complement Alternat Med 2013;2013(2):378657.

23. Rupeshkumar M, Kavitha K, Haldar PK. The role of herbal plants in the diabetes mellitus therapy: An overview. Int J Appl Pharm 2014;6(3):1-3.

24. Bhavesh CV, Siddharth JM, Jignasa KS, Snehal SP. In silico molecular docking and pharmacokinetic prediction of gallic acid herbal derivatives as ppar- $\gamma$ agonists. Int J Pharm Pharm Sci 2017;9(1):102-7.

25. Punabaka J, Kuna Y. Molecular docking studies on the therapeutic targets of Alzheimer disease ( $\mathrm{AChE}$ and $\mathrm{BChE}$ ) using natural bioactive alkaloids. Int J Pharm Pharm Sci 2016;8(12):108-12.

26. Akshada J, Manoj G, Urmila JJ. Identification of potential novel EGFR inhibitors using a combination of pharmacophore and docking methods. Int J Pharm Pharm Sci 2015;7(6) 77-91.

27. Klebe G. Recent developments in structure-based drug design. J Mol Med (Berl) 2000;78(5):269-81.

28. Tollenaere JP. The role of structure-based ligand design and molecular modelling in drug discovery. Pharm World Sci 1996;18(2):56-62.

29. Anderson AC. The process of structure-based drug design. Chem Biol 2003;10(9):787-97.

30. Jorgensen WL. The many roles of computation in drug discovery. Science 2004;303(5665):1813-8

31. Schneider G, Fechner U. Computer-based de novo design of drug-like molecules. Nat Rev Drug Discov 2005;4:649-63.

32. Ochieng PJ, Kusuma WA, Rafi M, Sumaryada T. Deciphering the action mechanism of Indonesia herbal decoction in the treatment of type II diabetes using a network pharmacology approach. Int J Pharm Pharm Sci 2017;9(3):243-53.

33. Wang Y, Xiao J, Suzek TO, Zhang J, Wang J, Bryant SH. PubChem: A public information system for analyzing bioactivities of small molecules. Nucleic Acids Res 2009;37(Web Server issue):W623-33.

34. Laskowski RA, Hutchinson EG, Michie AD, Wallace AC, Jones ML, Thornton JM. PDBsum: A Web-based database of summaries and analyses of all PDB structures. Trends Biochem Sci 1997;22(12):488-90.

35. Trott O, Olson AJ. AutoDock Vina: Improving the speed and accuracy of docking with a new scoring function, efficient optimization, and multithreading. J Comput Chem 2010;31(2):455-61.

36. Morris GM, Huey R, Lindstrom W, Sanner MF, Belew RK, Goodsell DS, et al. AutoDock4 and AutoDockTools4: Automated docking with selective receptor flexibility. J Comput Chem 2009;30(16):2785-91.

37. Sherman W, Day T, Jacobson MP, Friesner RA, Farid R. Novel procedure for modeling ligand/receptor induced fit effects. J Med Chem 2006;49(2):534-53.

38. Schnecke V, Kuhn LA. Virtual screening with solvation and ligand-induced complementarity. Perspect Drug Discov Design 2000;20(1):171-90.

39. Laskowski RA, Swindells MB. LigPlot+: Multiple ligand-protein interaction diagrams for drug discovery. J Chem Inf Model 2011;51(10):2778-86

40. Perola E, Walters WP, Charifson PS. A detailed comparison of current docking and scoring methods on systems of pharmaceutical relevance. Proteins 2004;56(2):235-49.

41. Cheng F, Li W, Zhou Y, Shen J, Wu Z, Liu G, et al. admetSAR: A comprehensive source and free tool for assessment of chemical ADMET properties. J Chem Inf Model 2012;52(11):3099-105.

42. Ertl P, Rohde B, Selzer P. Fast calculation of molecular polar surface area as a sum of fragment-based contributions and its application to the prediction of drug transport properties. J Med Chem 2000;43:3714-7.

43. Lipinski CA. Lead-and drug-like compounds: The rule-of-five revolution. Drug Discov Today Technol 2004;1(4):337-41.

44. Lipinski CA, Lombardo F, Dominy BW, Feeney PJ. Experimental and computational approaches to estimate solubility and permeability 
in drug discovery and development settings. Adv Drug Deliv Rev 2001;46(1-3):3-26

45. Lagunin A, Stepanchikova A, Filimonov D, Poroikov V. PASS: Prediction of activity spectra for biologically active substances. Bioinformatics 2000;16(8):747-8.

46. Warren GL, Warren SD. Scoring drug-receptor interaction. In: Gramatica P, Livingstone DJ, Davis AM. Drug Design Strategies: Quantitative Approaches. Ch. 16, Vol. 440. Cambridge U.K.: Royal Society Chemistry: 2011. p. 57.

47. Yuan Y, Pei J, Lai L. Binding site detection and druggability prediction of protein targets for structure-based drug design. Curr Pharm Des 2013;19(12):2326-33.

48. Leis $\mathrm{S}$, Schneider $\mathrm{S}$, Zacharias M. In silico prediction of binding sites on proteins. Curr Med Chem 2010;17(15):1550-62.

49. Sim L, Jayakanthan K, Mohan S, Nasi R, Johnston BD, Pinto BM, et al. New glucosidase inhibitors from an ayurvedic herbal treatment for type 2 diabetes: Structures and inhibition of human intestinal maltaseglucoamylase with compounds from Salacia reticulata. Biochemistry 2010;49(3):443-51.

50. Ren L, Qin X, Cao X, Wang L, Bai F, Bai G, et al. Structural insight into substrate specificity of human intestinal maltase-glucoamylase. Protein Cell 2011;2(10):827-36.

51. Sim L, Willemsma C, Mohan S, Naim HY, Pinto BM, Rose DR. Structural basis for substrate selectivity in human maltaseglucoamylase and sucrase-isomaltase $\mathrm{N}$-terminal domains. J Biol Chem 2010;285(23):17763-70.

52. Balani SK, Miwa GT, Gan LS, Wu JT, Lee FW. Strategy of utilizing in vitro and in vivo ADME tools for lead optimization and drug candidate selection. Curr Top Med Chem 2005;5(11):1033-8.

53. Tetko IV, Bruneau P, Mewes HW, Rohrer DC, Poda GI. Can we estimate the accuracy of ADME-Tox predictions? Drug Discov Today 2006;11(15-16):700-7.

54. Yu H, Adedoyin A. ADME-Tox in drug discovery: Integration of experimental and computational technologies. Drug Discov Today 2003;8(18):852-61.

55. Singh SS. Preclinical pharmacokinetics: An approach towards safer and efficacious drugs. Curr Drug Metab 2006;7(2):165-82.

56. Srimai V, Ramesh M, Satya PK, Parthasarathy T. Computer-aided design of selective cytochrome P450 inhibitors and docking studies of alkylresorcinol derivatives. Med Chem Res 2013;22(4):5314-23.

57. Chang LC, Spanjersberg RF, von Frijtag Drabbe Künzel JK, Mulder-Krieger T, van den Hout G, Beukers MW, et al. 2,4,6-trisubstituted pyrimidines as a new class of selective adenosine A1 receptor antagonists. J Med Chem 2004;47(26):6529-40.

58. Veber DF, Johnson SR, Cheng HY, Smith BR, Ward KW, Kopple KD. Molecular properties that influence the oral bioavailability of drug candidates. J Med Chem 2002;45(12):2615-23.

59. Lynch T, Price A. The effect of cytochrome P450 metabolism on drug response, interactions, and adverse effects. Am Fam Physician 2007;76(3):391-6.

60. Sharom FJ. The P-glycoprotein efflux pump: How does it transport drugs? J Membr Biol 1997;160(3):161-75.

61. Verma N, Amresh G, Sahu PK, Rao ChV, Singh AP. Antihyperglycemic and antihyperlipidemic activity of ethyl acetate fraction of Rhododendron arboreum Smith flowers in streptozotocin induced diabetic rats and its role in regulating carbohydrate metabolism. Asian Pac J Trop Biomed 2012;2(9):696-701.

62. Madar Z. The effect of acarbose and miglitol (BAY-M-1099) on postprandial glucose levels following ingestion of various sources of starch by nondiabetic and streptozotocin-induced diabetic rats. J Nutr 1989;119(12):2023-9.

63. Bischoff $H$. The mechanism of alpha-glucosidase inhibition in the management of diabetes. Clin Invest Med 1995;18(4):303-11.

64. Tadera K, Minami Y, Takamatsu K, Matsuoka T. Inhibition of alphaglucosidase and alpha-amylase by flavonoids. J Nutr Sci Vitaminol (Tokyo) 2006;52(2):149-53.

65. Mayor F Jr., Lucas E, Jurado-Pueyo M, Garcia-Guerra L, Nieto-Vazquez I, Vila-Bedmar R, et al. G Protein-coupled receptor kinase 2 (GRK2): A novel modulator of insulin resistance. Arch Physiol Biochem 2011;117(3):125-30.

66. Shahid G, Hussain T. GRK2 negatively regulates glycogen synthesis in mouse liver FL83B cells. J Biol Chem 2007;282(28):20612-20.

67. Carotenuto A, Cipolletta E, Gomez-Monterrey I, Sala M, Vernieri E, Limatola A, et al. Design, synthesis and efficacy of novel G protein-coupled receptor kinase 2 inhibitors. Eur J Med Chem 2013;69(8):384-92

68. Jerad SA, Devi R, Noorulla KM, Surya PR. Insights into thioridazine for its anti-tubercular activity from molecular docking studies. Int $\mathrm{J}$ Pharm Pharm Sci 2015;7(3):344-6.

69. Usui I, Imamura T, Satoh H, Huang J, Babendure JL, Hupfeld CJ, et al. GRK2 is an endogenous protein inhibitor of the insulin signaling pathway for glucose transport stimulation. EMBO J 2004;23(14):2821-9.

70. Homan KT, Tesmer JJ. Molecular basis for small molecule inhibition of G protein-coupled receptor kinases. ACS Chem Biol 2015;10(1):246-56. 